\title{
3D modeling of deepwater turbidite lobes: a review of the research status and progress
}

\author{
Lei-Fu Zhang ${ }^{1,2,3,4} \cdot$ Mao Pan $^{5} \cdot$ Zhao-Liang Li $i^{5,6}$
}

Received: 16 November 2018 / Published online: 4 February 2020

(c) The Author(s) 2020

\begin{abstract}
Deepwater turbidite lobe reservoirs have massive hydrocarbon potential and represent one of the most promising exploration targets for hydrocarbon industry. Key elements of turbidite lobes internal heterogeneity include the architectural hierarchy and complex amalgamations at each hierarchical level leading to the complex distribution of shale drapes. Due to limitation of data, to build models realistically honoring the reservoir architecture provides an effective way to reduce risk and improve hydrocarbon recovery. A variety of modeling techniques on turbidite lobes exist and can be broadly grouped into pixel-based, process-based, process-oriented, surface-based, object-based and a hybrid approach of two or more of these methods. The rationale and working process of methods is reviewed, along with their pros and cons. In terms of geological realism, object-based models can capture the most realistic architectures, including the multiple hierarchy and the amalgamations at different hierarchical levels. In terms of data conditioning, pixel-based and multiple-point statistics methods could honor the input data to the best degree. In practical, different methods should be adopted depending on the goal of the project. Such a review could improve the understanding of existing modeling methods on turbidite lobes and could benefit the hydrocarbon exploration activities of such reservoirs in offshore China.
\end{abstract}

Keywords Turbidite lobes $\cdot$ Architectural hierarchy $\cdot$ Architecture element $\cdot$ Stochastic modeling $\cdot$ Sand amalgamation

\section{Introduction}

Turbidite lobes are lobate depositional features occurring in distal reaches of turbidite systems as terminal splays of deepwater channels. Turbidite lobe reservoirs have become one of the most promising targets for oil and gas exploration over the

Edited by Jie Hao and Xiu-Qiu Peng

Lei-Fu Zhang

zhangleifu@petrochina.com.cn

1 Fault Analysis Group, School of Geological Sciences, University College Dublin, Dublin, Ireland

2 Present Address: PetroChina Research Institute of Petroleum Exploration and Development, Beijing, China

3 Present Address: National Energy Shale Gas Research (Experiment) Center, Beijing, China

4 Present Address: CNPC Key Laboratory of Unconventional Oil and Gas, Beijing, China

5 School of Earth and Space Science, Peking University, Beijing, China

6 China Aero Geophysical Survey and Remote Sensing Center for Natural Resources, Beijing, China past two decades (Howell et al. 2014). Reservoir architecture determines the heterogeneity and connectivity of the reservoir (e.g., Pyrcz and Deustch 2014) and is the key to improve the hydrocarbon recovery (Wu et al. 2008a, b). Although characterized by high lateral continuity and rather flat geometry, turbidite lobes are not simply tabular, non-channelized sheetlike bodies that gradually pinch out as suggested by previous geologists (e.g., Mutti and Normark 1987). Instead, recent research using high-resolution seismic data and detailed outcrop characterizations have concluded that deepwater lobe deposits internally show much more facies complexity than previously thought for being structured hierarchically (Gervais et al. 2006; Deptuck et al. 2008; Saller et al. 2008; Prelat et al. 2009; Grundvåg et al. 2014) and that their geometry and internal partitioning can be influenced by basin topography (Marini et al. 2011, 2015, 2016). In this hierarchy, sand-prone lobe hierarchical components are commonly defined as being well separated by mud-prone bounding units and therefore not well connected. However, high-resolution outcrop studies have demonstrated that the mud-prone bounding units are not as continuous as the conceptual hierarchical scheme implies. Instead, they can be locally amalgamated (e.g., Marini et al. 2015) giving rise to direct contacts of sand-prone lobe 
hierarchical units. Despite documented and recognized as key in controlling static reservoir connectivity and flow behavior (e.g., Stephen et al. 2001; Manzocchi et al. 2007; Zhang et al. 2013), amalgamations of component units of turbidite lobe have not been assessed quantitatively and embedded in reservoir modeling workflows.

Numerical modeling is a vital tool for understanding subsurface reservoirs. For reservoirs, complex facies complexity and multiple architecture hierarchy are directly associated with rock properties and flow behaviors. Three-dimensional (3D) reservoir models integrating available datasets and geological concepts can provide accurate reproduction of the subsurface, properties at inter-well regions can be predicted, uncertainties and heterogeneities can be addressed by generating multiple realizations and scenarios. Numerical modeling is utilized at all stages from appraisal, production, IOR (increased oil recovery) to decommissioning stage to facilitate the field abandonment (Howell et al. 2014).

Geostatistical modeling has become a research focus recently, and many modeling methods have been published (e.g., Pyrcz et al. 2005; Manzocchi et al. 2007; Zhang et al. 2009; Groenenberg et al. 2010; Bertoncello et al. 2013; Albertão et al. 2015; Pyrcz et al. 2015; Wang et al. 2018). However, several problems still exist: (1) In particular at exploration stage, the conditioning data and direct observations on sedimentary facies (i.e., continuous coring boreholes) used for modeling turbidites lobes are commonly of too low resolution or too sparse (i.e., low-quality seismic data, limited number of wells) for accurately reconstructing the 3D spatial distribution of fine-scale component elements of turbidite lobes; (2) despite their importance, the internal hierarchy of lobes and the degree and mode of amalgamation of lobe component elements are commonly overlooked. The objective of this paper, therefore, is to review the modeling method and particularly the existing work and research frontiers on deepwater lobe modeling, in order to provide useful insights for understanding the concepts, methodologies and the pros and cons of different modeling techniques. To be specific, classical modeling approaches are briefly discussed at first, then the benefit of recent methods over classical methods is reviewed in detail. These could, in turn, greatly benefit the deepwater exploration by reducing the risk and improving the development efficiency.

\section{Key deepwater lobe architectural characteristics}

\subsection{Architecture hierarchy}

Conceptually, the deepwater lobe architecture anatomy can be divided into several hierarchies (e.g., Deptuck et al. 2008;
Prelat et al. 2009). At each hierarchical level, thick sand bodies are separated by relatively continuous and parallel thinner mud drapes, representing the mud caps of single turbidite beds (i.e., "event" beds) or packages of thin-bedded turbidites. From proximal to distal, lobes can be divided into axis, off-axis, fringe and distal lobe fringe, with a decrease of thickness and grain size (Prelat et al. 2009).

Although the dimensions may vary, the hierarchical nature of deepwater lobe architectural elements has been solidly recognized both based on plan-form geometries (e.g., Deptuck et al. 2008) and vertical compartmentalizations (e.g., Prelat et al. 2009). For example, using subsurface data, four hierarchical levels of compensational stacking in plan view were recognized in the Golo systems (Deptuck et al. 2008), with "beds" stacking to form "lobe elements," "lobe elements" stacking to form "composite lobes," and "composite lobes" stacking to form "lobe complex" (Fig. 1). Hierarchical subdivisions were recognized primarily according to the abruptness of the shift between the thickest parts of successive bodies, and secondarily based on bounding discontinuities and the amount of drape between depositional bodies. In contrast, outcrop studies generally allow high-resolution vertical observations, but these observations cannot be correlated over wide distances. Hence, the definition of the hierarchy in outcrop studies is commonly based on bounding surfaces separating depositional bodies. A great example is the Permian deepwater lobe deposits in Tanqua Karoo Basin, South Africa, in which a fourfold hierarchy from "bed" to "lobe element" to "lobe" to "lobe complex" has been recognized based on the characteristics and geometry of fine-grained units that bound the sand-prone bodies (Prelat et al. 2009; Fig. 1). The lobe hierarchical units are well separated by fine-grain units which are termed interlobe, inter-lobe element and inter-bed, respectively. This fourfold hierarchical scheme has been widely applied with slight modifications in recent literature on turbidite lobes from different systems (e.g., Marini et al. 2011, 2015; Zhang et al. 2017) and is adopted tout court in the present paper.

\subsection{Sandbody amalgamation}

The process by which turbidite sandstone beds are amalgamated forming composite beds has been frequently observed by sedimentologists dealing with turbidite lobe deposits around the globe (Stephen et al. 2001; Romans et al. 2009; Funk and Pyles 2012). The degree of amalgamations can be quantified using the amalgamation ratio of Chapin et al. (1994), which has been demonstrated to well quantify the static connectivity of turbidite sandstone (Stephen et al. 2001; Manzocchi et al. 2007). Therefore, after classifying lobe deposits based on hierarchy of component elements, it is important that the amalgamation ratio is defined and quantified for all of the recognized hierarchical scales 

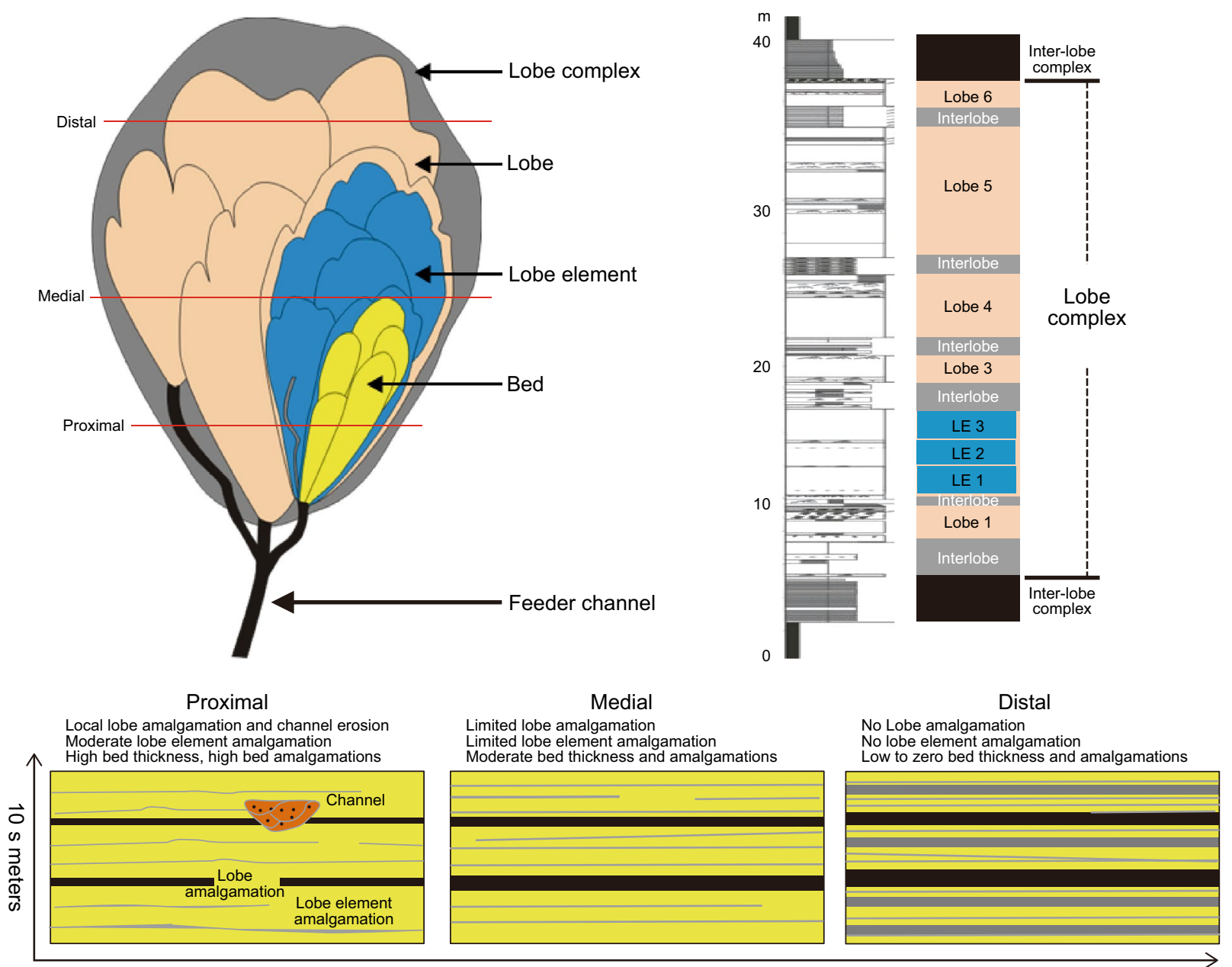

10 s kilometres

Fig. 1 Cartoon showing the fourfold hierarchy for lobe complexes, in plan-form, vertical section and cross sections, respectively. Modified from Prelat et al. (2009). Note that the relative scale and the number of objects at the different hierarchical levels are highly variable

(Zhang et al. 2013; Zhang et al. 2015).Excellent examples showing different scales of lobe amalgamation include the lobe deposits in the Tanqua Karoo Basin (Prelat et al. 2009, Fig. 2), the Central Basin of Spitsbergen, Arctic Norway (Grundvåg et al. 2014) and the Laga basin of the upper Miocene foreland basin system of Apennines (Marini et al. 2015). It is noteworthy that the high-level lobe components (e.g., lobe complexes) are more likely to separate from each other by very thick hemipelagic mudstones which makes them less prone to amalgamation.

Turbidite lobes are generally characterized by interbedded sandstones and mudstones which can be both laterally continuous. Sandstone connectivity is controlled by sand fraction (net to gross ratio) and degree of amalgamations (amalgamation ratio); intervals with high sand fraction do not necessarily possess high connectivity (Fig. 3a).
Different architectural elements of turbidites are likely to be characterized by different net to gross ratio and amalgamation ratio relationships (Fig. 3b). Whichever the hierarchical scale, amalgamation leads to erosion of their fine-grained deposits which bound component element of lobes and act as key flow barriers (e.g., inter-lobes), thereby resulting in a higher connectivity of the reservoir parts of lobes. To effectively incorporate these hierarchical amalgamations into reservoir models is hence vital to realistically represent the reservoir connectivity and heterogeneity. However, this requires that the hierarchical amalgamations are quantified as input parameters. Since it is virtually impossible to recognize the amalgamations using subsurface data (well logging, seismic), to quantitatively compile existing outcrop studies where the hierarchical amalgamations are documented is thus essential. 


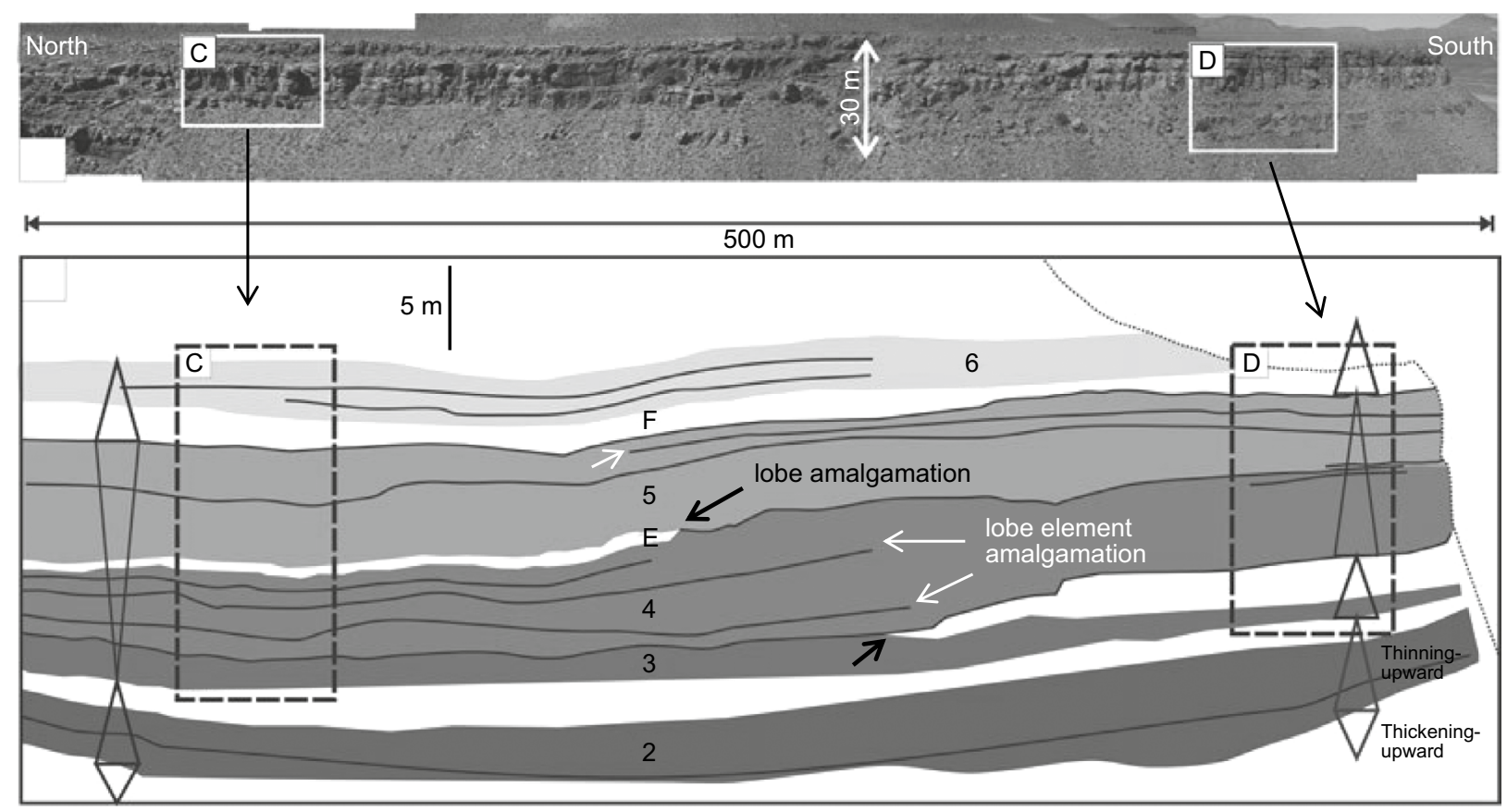

Fig. 2 Outcrop interpretations showing lobe amalgamations (black arrows) and lobe element amalgamations (white arrows). Individual lobe is labeled as numbers (2-6) and inter-lobe is labeled C-F. Within each lobe, the black lines represent the inter-lobe element shales. Modified from Fig. 17 of Prelat et al. (2009)
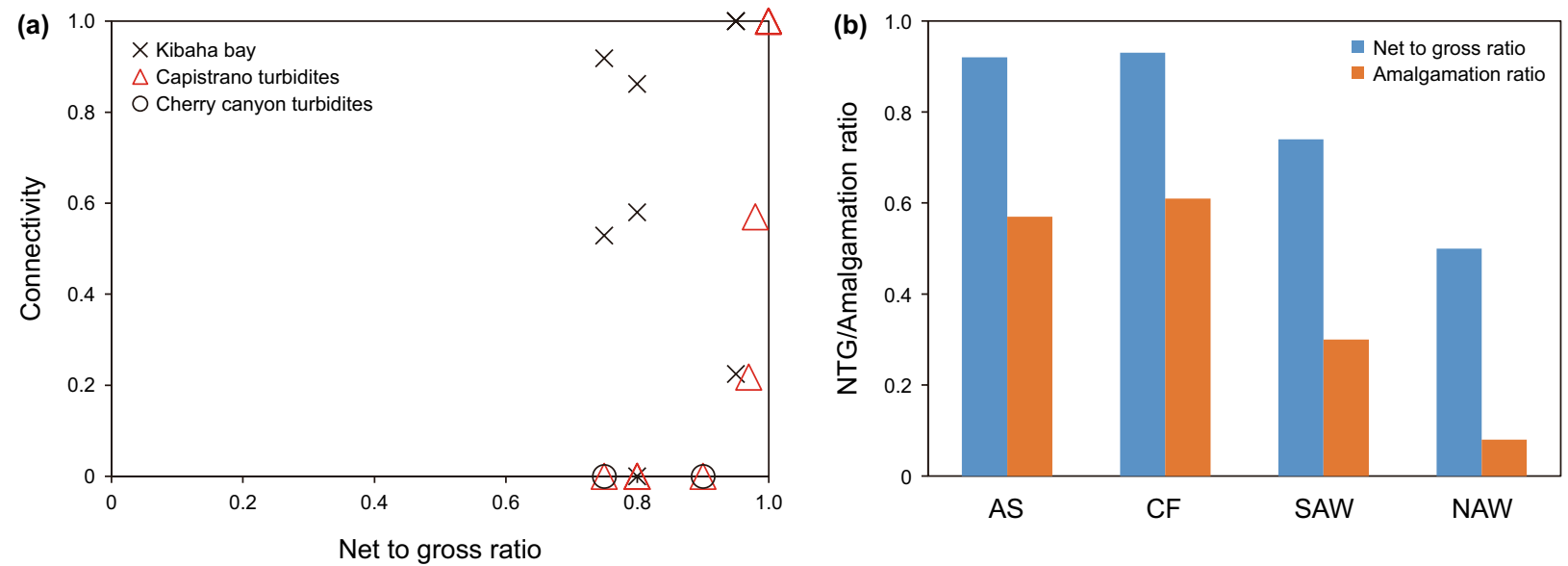

Fig. 3 a Compilation of Net to gross ratio and static connectivity for different environments, data are from Funk and Pyles (2012). b Net to gross ratio and amalgamation ratio for different elements in the Tres Pasos turbidites, modified from Romans et al. (2009). $A S$ amalgamated sheets; $C F$ channel form-fill; SAW semi-amalgamated wedges; and NAW non-amalgamated wedge

\section{Stochastic reservoir modeling of turbidite lobes}

In a typical reservoir model workflow, after a depositional model has been conceptualized including definition of sedimentary facies, architectural elements and hierarchy, a decision must be made upon the modeling technique to be used for modeling the 3D spatial distribution of the lowest rank building block of the reservoir, which is sedimentary facies or facies association. After accurate characterization, facies/facies association models are then converted into petrophysical models. Existing algorithms commonly used in geostatistical modeling of reservoirs can be broadly grouped into three categories of alternative techniques: pixel-based methods, multiple-point statistics and object-based methods (Pyrcz and Deutsch 2014). 
Pixel-based methods are based on assigning properties to grid cells according to the occurrence probability distribution function (PDF), which is computed for each grid cell. These methods allow direct conditioning by hard data and can be used for the stochastic modeling of discrete (e.g., rock types) and continuous attributes (e.g., porosity and permeability). It can be achieved by a number of algorithms such as indicator Kriging, truncated Gaussian simulation (TGS) and sequential indicator simulation (SIS). The sequential indicator simulation (SIS) is the most commonly used method and commonly applied in commercial packages. When modeling a reservoir using SIS after defining operative facies, the first step is to compute spatial proportions and semivariograms that are needed to inform the algorithm on size and spatial distribution of facies in the model unit. Secondly, the attribute to be modeled is described through a binary indicator variable (e.g., seismic impedance). It takes the value "1" if the attribute is encountered at a given location and " 0 " otherwise. The indicator variable is in turn defined by its average frequency and a semivariogram that characterizes the spatial continuity (Seifert and Jensen 1999). Thirdly, the SIS method assigns the attribute to each grid cell sequentially, following a random path through the three-dimensional grid. Although the SIS method can well honor the input data (e.g., facies proportions from wells) and has been proven effective in many case studies (e.g., Seifert and Jensen 1999), there are two limitations with such pixel-based modeling. The first limitation is that it is difficult to model architectures with well-defined margins and discrete shapes because the geostatistical algorithms tend to create smoothly varying fields (Ringrose and Bentley 2015). By contrast, objectbased modeling is preferable when the model units have well-defined geometries and hierarchies (e.g., fluvial channels and turbidite lobes). The second limitation is that the semivariograms will always be applied along a linear axis of anisotropy therefore leading to relatively linear features (Seifert and Jensen 2000). The variogram-based SIS method is based on "two-point" statistics, in other words, it accounts for correlation between pairs of points only. This limitation has been overcome by the modeling using multiple-point statistics.

The multiple-point geostatistics (MPS), which has been proposed and developed quite recently (Caers 2001; Strebelle et al. 2003; Yin et al. 2008), represents an improvement because it characterizes the spatial structure by considering several points. Although the MPS method is also pixel-based, it does not require any preliminary data transformation and thus is grouped as an independent modeling method herein. The MPS starts with scanning a training image within a fixed dimension. The training image (2D or 3D) provides a conceptual description of the geological heterogeneity; it can be an unconditional realization generated by an object-based algorithm, or a simulated realization of an analogous field, or simply a geologist's sketch processed with computer-aided design tools and properly digitized (Strebelle et al. 2003). The next step of MPS method is to scan all the grid nodes based on the template of training image; the frequency of instances of a model element occurring next to similar and different elements are recorded, as is their relative position (Strebelle et al. 2003). It looks for patterns matching the training image and then computes the probabilities and draw simulated value.

Unlike the pixel-based modeling discussed above, the object-based modeling places bodies with specific shapes in 3D space, while another model element (or a group of model elements) is defined as the background (Holden et al. 1998). The object-based modeling is based on the "marked point process" (Holden et al. 1998): The marked point is a position in the 3D volume and is selected randomly. To this point, object which is assigned to a series of parameters like shape template, dimension and orientation is placed into a model initialized with a background until some predefined criteria is reached (e.g., the proportion of the object).

The object-based modeling includes two steps. The first step is to define a series of properties (e.g., dimensions, shapes) to the object to be modeled, based on outcrop analogues or well data. At this step, rules constraining the placement of the objects are also applied (e.g., erosions, intersections). The next step is to place objects into 3D volume, in contrast to the pixel-based modeling that assigns data to the models cells and proceeds along a random path. The object-based techniques are a considerable improvement over traditional variogram-based methods in terms of well capturing the architectures with clear geometries and margins. They have been proven effective in modeling those reservoirs where facies are organized in clear geometric units and so that can be easily parameterized as objects with simple shapes. The successful applications of objectbased modeling include modeling the fluvial channels (e.g., Deutsch and Tran 2002), deepwater channelized deposits (e.g., Larue and Hovadik 2006) and deepwater sheet-like deposits (e.g., Stephen et al. 2001; Manzocchi et al. 2007; Zhang et al. 2013, 2015).

Reservoir elements of deepwater lobe deposits are well organized into a hierarchical manner and they are the objectives of the current paper. Existing modeling work focusing on turbidite lobes are reviewed below. Beside those described above, there are a number of alternative modeling methods which cannot be easily be grouped as "pixel-based" or "object-based." Instead, the modeling methods used are named according to the most characteristic property of the modeling. Such modeling work includes process-based, process-oriented, surface-based and object-based modeling. They are discussed below in detail along with their pros and cons. 


\subsection{Object-based modeling}

An important feature of deepwater lobe reservoirs is that their architectural elements are structured into a hierarchical manner with certain lobate geometries which could be well parameterized (e.g., dimensions, shapes) and show an overall sand-mud binary fashion, all suggesting objectbased modeling method is a suitable approach to model such reservoirs (Pyrcz and Deutsch 2014). Object-based modeling techniques have been widely applied to depositional systems which are characterized by apparent shapes and geometries, for example the fluvial and turbidite channel systems (e.g., Larue and Hovadik 2006) and turbidite lobe systems (Deutsch and Tran 1999; Stephen et al. 2001; Manzocchi et al. 2007; Zhang et al. 2013, 2015). Notably, Deutsch and Tran (1999) proposed the "LOBESIM" program that deals with channel, levee and lobe facies models. However, it seems like few studies on deepwater lobes using this program have been published since. Stephen et al. (2001) generated a series of Monte Carlo realizations of 2D cross-sectional models including interbedded shales and sandstone beds. In their models, the shales beds are locally removed giving rise to sand-on-sand contacts so that a certain amalgamation ratio can be characterized (Fig. 4). The resulting models with specific amalgamation ratios were flow simulated, and the results demonstrated that the amalgamation ratio can be related to the single-phase upscaled ratio of vertical to horizontal permeability by a log-linear relationship and to the fraction of oil recovered by a linear relationship.

Manzocchi et al. (2007) used an object-based modeling approach (vbFIFT) to generate a suite of 3D bed-scale models under a principle that when each sandstone bed is placed, and it has the potential to be erosive over its entire length. This method is based on a "compression method." First, vbFIFT generates a random system with a net/gross ratio equivalent to the target amalgamation ratio. Second, all cells containing shale are compressed vertically with respect to those containing sand. The degree of compression is controlled by a parameter $C_{\mathrm{F}}=\left(1-\mathrm{NTG}^{-1}\right) /\left(1-\mathrm{AR}^{-1}\right)$. The resultant (thinner) models have a lower net/gross ratio than the initial model but the same amalgamation ratio. Conventional modeling work uses the net/gross ratio as the key controlling parameter and has an underlying assumption that the net/gross ratio is equivalent to the amalgamation ratio (e.g., Larue and Hovadik 2006). However, it has been demonstrated that the amalgamation ratio of natural systems is usually significantly lower than the net/gross ratio (e.g., Fig. 3), and hence, conventional models tend to be more connected than a natural system at the same net/gross ratio.
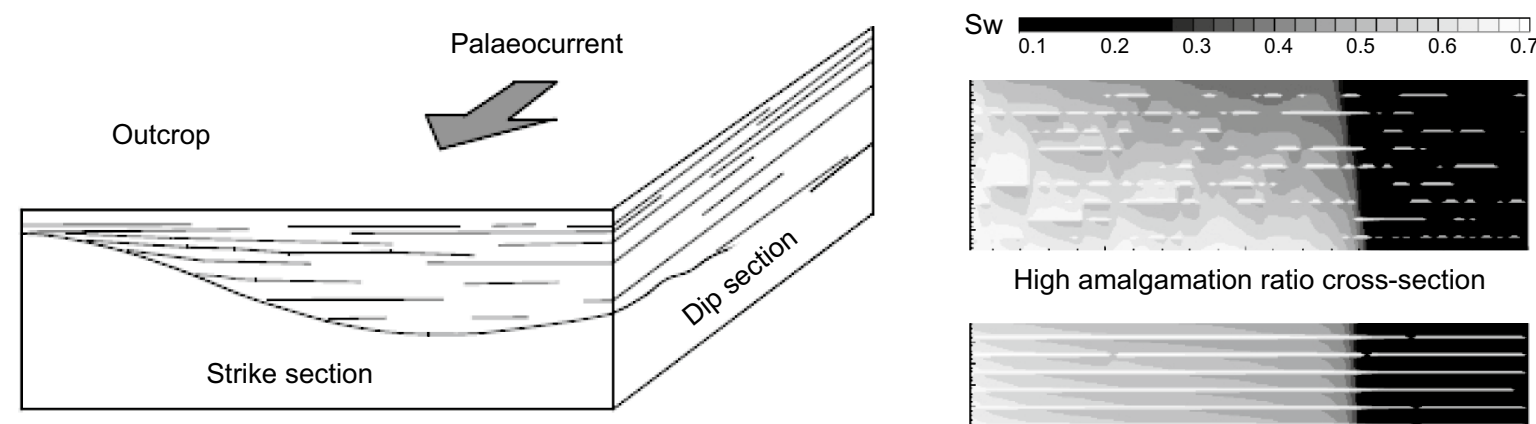

High amalgamation ratio cross-section

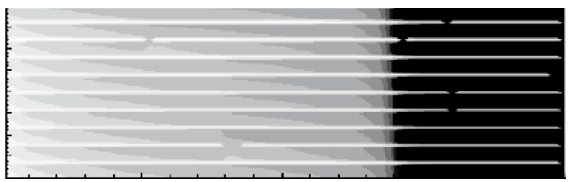

Low amalgamation ratio cross-section

Amalgamation surface (shale eroded away)
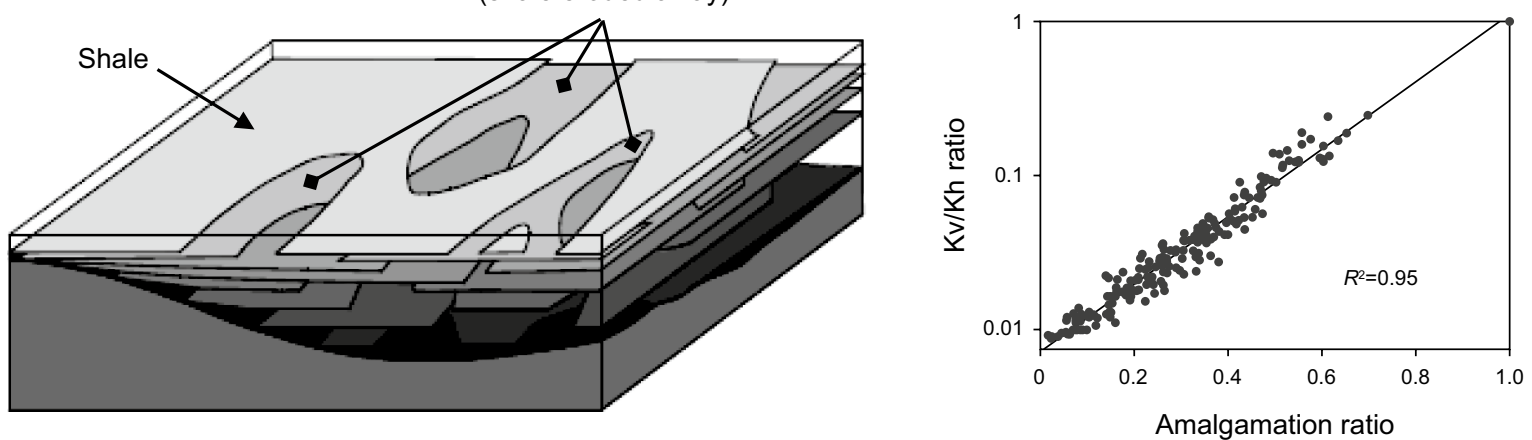

Fig. 4 Cartoon showing amalgamation surfaces and the relationship of amalgamation ratio and flow performances for turbidites, modified from Stephen et al. (2001) 
A unique advantage of vbFIFT modeling method over conventional modeling method is that vbFIFT allows generating models with independent NTG and AR as input parameters.

The connectivity of sandstone beds is a fundamental control on the eventual hydrocarbon recovery of a reservoir (e.g., King 1990; Larue and Legarre 2004). Static connectivity can be defined as the fractional volume of the largest connected cluster (Ainsworth 2005; Larue and Hovadik 2006). Manzocchi et al. (2007) used vbFIFT to model a series of faulted and unfaulted turbidites and demonstrated that for unfaulted turbidites (Fig. 5), AR is the dominant control on connectivity. When AR is low, the final connectivity can be lower than $10 \%$ even if NTG exceeds $90 \%$. For faulted models, the connectivity is controlled by complex interactions of multiple structural and sedimentological factors. Having noted that the complete lobe architectural hierarchy and the amalgamations at each hierarchical level are not fully honored, the vbFIFT method has been modified in such a way that these two problems could be tackled.

Zhang et al. $(2013,2015)$ used the modified version of vbFIFT to build a suite of lobe models that have the complete hierarchy and associated amalgamations. Their output lobe models better characterize the bed-lobe element-lobe hierarchy, the pinch out geometry of hierarchical units and their amalgamation features compared to other modeling studies. When assuming the shales are impermeable, intense pressure stratification at the onset of production in the hierarchical models with a lower lobe element amalgamation is associated with poor performance in terms of both production rates and sweep efficiency (Zhang et al. 2015).
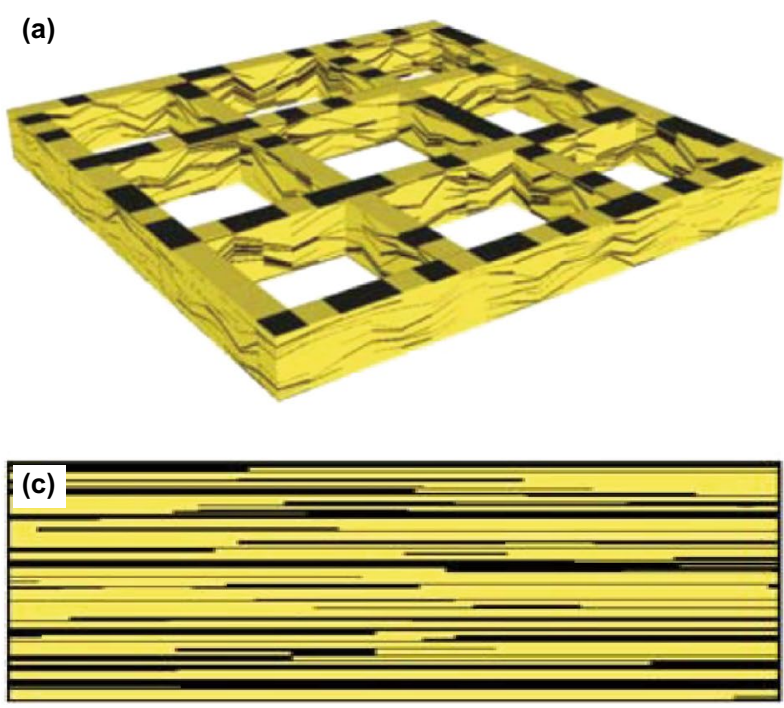

The possible problems associated with these objectbased modeling work are as follows. First, to realistically model the amalgamations is key to represent the reservoir architecture and compartmentalization. Although some amalgamations have been incorporated into modeling, the amalgamation characteristics at different hierarchical scales require more solid parameterization. Second, channels that feed distributary lobes could be preserved and erode into the proximal lobes and might modify the overall connectivity; however, channels are not well modeled. Third, it is sometimes impossible to condition object-based models to dense dataset, and the run-time can be large for large models. Updating of models is also inconvenient. Wang et al. (2018) presented a promising optimization-simulation methodology allowing conditioning 3D object-based fluvial models to dense well data. However, limitations associated with object parameterization and conditioning to soft data exist. Also, the extent to which this methodology can be applied to turbidite modeling remains unknown.

\subsection{Process-based modeling}

Process-based modeling uses physical equations to simulate the fundamental depositional processes to produce a numerical representation of the reservoir geology. There are many published studies regarding modeling of sedimentological and stratigraphic processes (e.g., SEDSIM, Tetzlaff 1991; Alluvism, Pyrcz et al. 2009). Delft 3D software, which has been widely applied in hydrodynamic modeling, is also used to model depositional process (e.g., Wang et al. 2016).
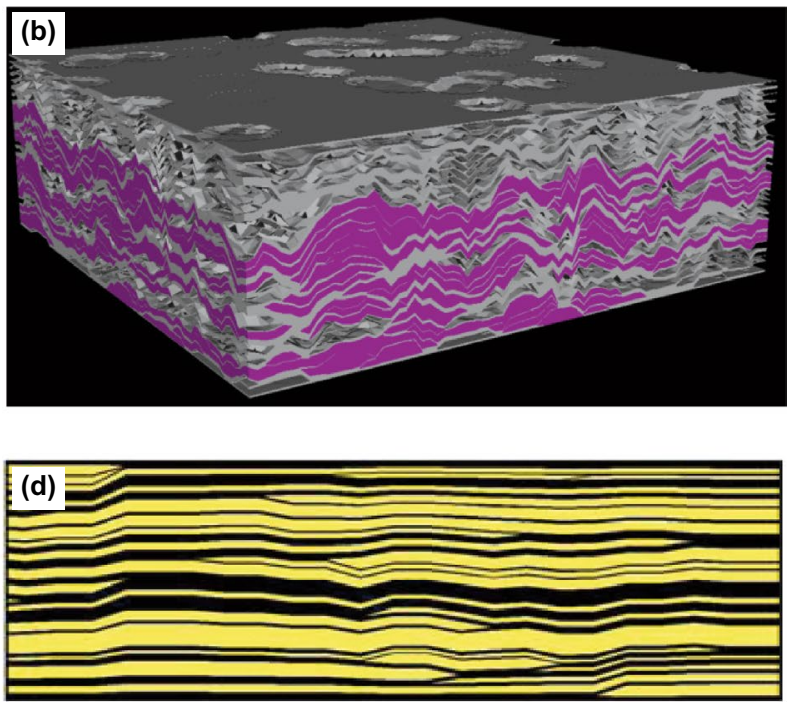

Fig. 5 a Schematic example output vbFIFT lobe model $(\mathrm{NTG}=0.8$, Amalgamation ratio $=0.55)$ with sandstone in yellow and mudstone in black. b The largest cluster in purple formed by mutually connected sandstone beds, the fraction of this cluster volume relative to the whole model volume gives the static connectivity. c Traditional object-based models by placing sandstone beds (yellow) into a mud background (black). $\mathbf{d}$ Models with the same NTG $=0.65$, bed size distributions as $\mathbf{c}$ generated by the compress-based modeling method. All modified from Manzocchi et al. (2007) 
Notably, Li et al. (2013) noticed the erosion of mud drapes in fluvial point-bars and improved the Alluvsim algorithm to realistically represent the partly erosion of mud drapes (i.e., amalgamation of fluvial channel). However, published process-based modeling work focusing on deepwater lobes is relatively less.

Reza et al. (2006) proposed ModDRE" (Modeling Deepwater Reservoir Elements) which is a process-based technique able to honor the morphological and sequence stratigraphy factors. Three architectural elements are considered: channel, lobe, hemipelagite. Bathymetric data can be directly incorporated as input and realistic geological and engineering attributes can be well integrated into the reservoir models. Notably, this technique allows representing erosions caused by both channels and lobes, models honoring realistic spatial distribution of architectural elements can be used as training image for MPS modeling. However, the erosions are not well quantified, and it is rather difficult to condition to real reservoir data (e.g., wells).

Groenenberg et al. (2010) used the outcrops of turbidite lobes in Tanqua Karoo as an analogue and aimed to better understand the interplay of allogenic and autogenic process. They have used a software called "FanBuilder" to generate conceptual process-based models. Input parameters include the initial bathymetry of the model domain and physical properties of flows (e.g., flow thickness, volume, velocity and concentration). Their models have successfully replicated some aspects of depositional architecture of lobes (e.g., finger-like pinch out geometries), suggesting that lobes do not fine and thin from the center in a simple manner (Fig. 6). Besides, the influence of underlying relief on the sites of deposition has been highlighted by their models, suggesting the importance of autogenic controls on the depositional architecture of deepwater lobe deposits. In their work, a bed-lobe element-lobe hierarchy is roughly captured by setting many single flow events (beds) into the modeling domain $6 \mathrm{~km}$ by $6 \mathrm{~km}$. Also using the FanBuilder software, Athmer et al. (2010) combined analogue sandbox experiments and numerical flow simulations to investigate the influence of relay ramps on the distribution of turbidite currents. This work considered the structural background and successfully modeled its theoretical control on the lobelike turbidite current.

Aas et al. (2014) used a process-based modeling software called "MassFLOW3D" to recreate the thickness and grainsize distribution of a single turbidite sandstone bed from the Peira Cava sub-basin of SE France. Although the broad deposition trend can be obtained within the majority of their simulation runs, the finer detail of the results varies greatly. Hawie et al. (2018) simulated the stratigraphic evolution of turbidite lobes in tectonically active slope basin with a series of diffusion-based DionisosFlow ${ }^{\mathrm{TM}}$ forward stratigraphic models, in which proper stratigraphic ordering and realistic compensational stacking are well represented. These
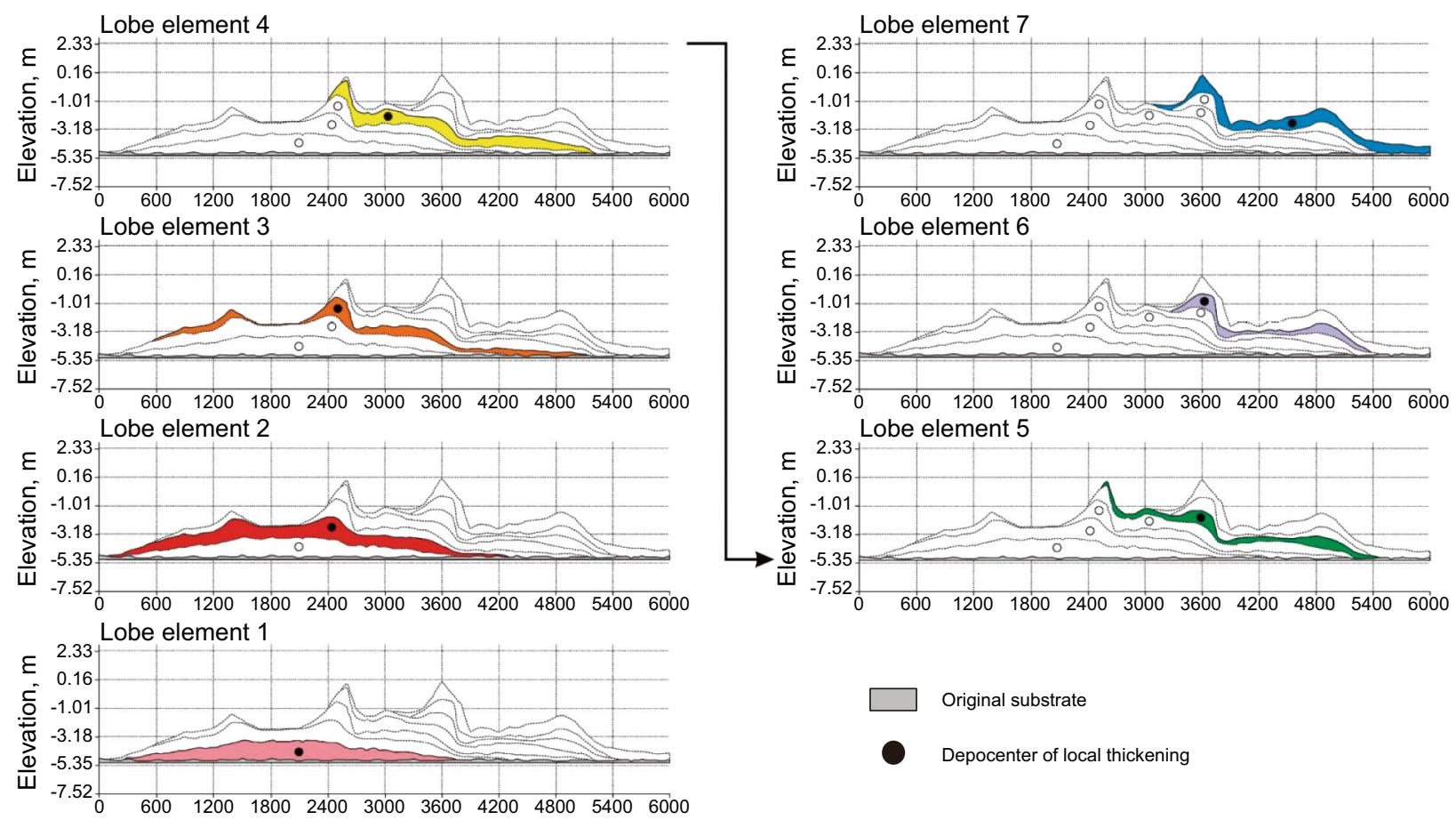

Length of cross-section profile, $m$

Fig. 6 Seven lobe elements showing compensational stacking in a lobe model. Modified from Groenenberg et al. (2010) 
process-based modeling studies are valuable since they help reveal the complicated interplay of sedimentary processes and the final architectures using the well-constrained analogues. Additionally, they can benefit the understanding of deepwater turbidity flow-deposit interactions, but shortcomings exist. First, there is a mismatch between the modeling results and outcrop analogues. In fact, it is difficult to condition process-based models to specific outcrop analogues and subsurface reservoirs. Second, although process-based modeling can represent multi-hierarchies, published examples focused on two-fold hierarchies, while failing to honor the complete lobe hierarchy (more than two-fold). Third, amalgamations between beds and lobe elements are not well quantified. The sequences are entirely depositional with no erosion in Groenenberg et al. (2010) and the models of Aas et al. (2014) focused only on a single bed; the improved Alluvism (Li et al. 2013) and MoDRE (Reza et al. 2006) method could represent sand body amalgamations resulting from complex interactions of multiple geological processes, but the amalgamations cannot be parameterized.

\subsection{Object-oriented modeling (SBED)}

The SBED software (an acronym for "Sedimentary Bedding", Geomodeling ${ }^{\mathrm{TM}}$ ) is a process-orientated, stochastic modeling approach allowing detailed digital reconstructions of fine-scale sedimentary reservoir heterogeneities (Wen 2005). This particular method focuses on simulating the results of the sedimentary process: the bedforms, rather than simulating the physical process ruling the genesis of sedimentary rocks (e.g., Stokes' Law) (Scaglioni et al. 2006). Therefore, it can not be simply grouped as the "processbased modeling" as discussed above. It focuses on smallscale bedding structures observed at core scales (where cell dimensions are millimeters to centimeters) and consists of building a time series of elevation surfaces corresponding to the sedimentary beddings. These surfaces are then sequentially migrated by vectors to simulate the lamina deposition, conditioned to certain geometric rules allowing new sets of surfaces to erode previously deposited laminas. The bedding geometries, bedform orientations, net/gross ratio and boundary conditions (e.g., eroded boundary) can be edited to represent core data. Resulting centimeters to millimetersscale SBED models can well honor the core measurements and the small-scale heterogeneities (e.g., Elfenbein et al. 2005, Fig. 7).

The process-oriented SBED approach has been applied to many non-marine depositional systems (e.g., fluvial channels). One important limitation of this approach is that it is focuses on such a fine scale that large-scale modeling (field scale) can be virtually difficult. Although the SBED approach has not been applied to turbidite lobes yet, it is the only existing software allows modeling the fine-scale bedding structures and relevant to the amalgamations since it allows the subsequent bedforms to erode previous ones. This function is similar to the critical function of the object-based modeling (vbFIFT) except the latter focuses on the erosions at larger scales (bed, lobe element and lobe) and therefore can well represent larger scale heterogeneities.

\subsection{Surface-based modeling}

As deposition processes occur, sedimentary surfaces are repeatedly formed and eroded. The preserved sedimentary surfaces can therefore effectively reflect the depositional processes. Surface-based modeling approach has been introduced recently (Pyrcz and Deutsch 2003; Pyrcz et al. 2005; Sech et al. 2009; Huang et al. 2013) to reproduce the end results created by depositional process rather than the physical process itself. The surface-based modeling approach has been applied to various depositional systems (e.g., turbidite channels, deltaic systems and turbidite lobes). Those published examples on surface-based modeling of turbidite lobes are of focus and discussed herein.

A group of workers have used surface-based techniques to generate geometric lobes characterized by bounding surfaces (top and bottom boundaries) (Pyrcz and Deutsch 2003; Pyrcz et al. 2005; Zhang et al. 2009) with a focus on representing the heterogeneity within reservoir elements constrained by surfaces. Two scales of hierarchy are considered in these studies: the small-scale geometries ("flow event deposits") and the large-scale geometries ("lobe") (Fig. 8). The flow event deposits were modeled within lobes by two steps. First, the geometry assigned to predefined aspects such as source location, bathymetry, flow path and characteristic shape is generated. Second, a stochastic residual account for fluctuations in the bounding

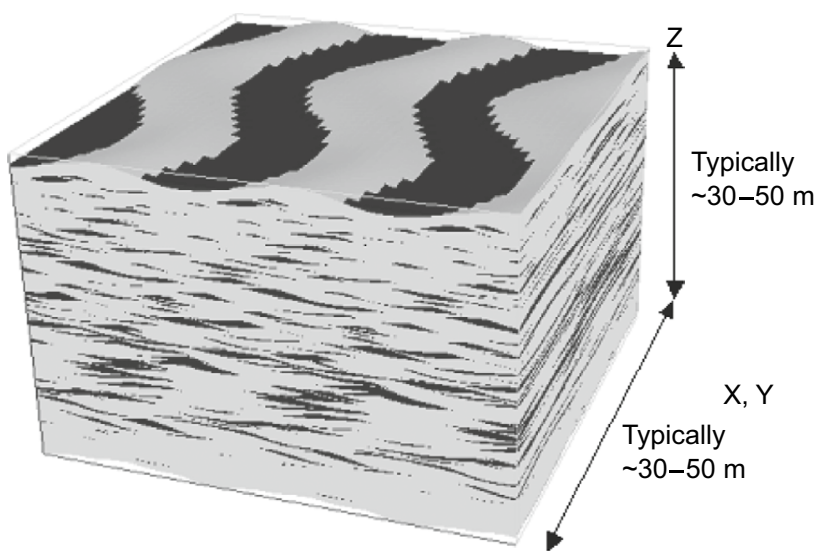

Fig. 7 An example output showing flaser-bedded heterolithic bedding model generated by the SBED software. Mud lamina is shown in dark and sand in light. Model size is about $50 * 50 * 50 \mathrm{~cm}$. Taken from Fig. 4 in Elfenbein et al. (2005) 
surfaces is added. The stochastic residual is characterized by a semivariogram model able to reflect the well data. If the surface geometry contradicts data outside a tolerance, the geometry is rejected. Their resulting models have well captured the geometries and the compensational stacking of small-scale flow events within reservoir-scale lobes. Lithofacies, porosity and permeability properties honoring the given data were assigned to the resulting geometric lobe models (Fig. 9). However, the facies properties are not directly simulated, and the convergence may be very slow when their models are conditioned to many wells. These shortcomings have been overcome by an improved surface-based modeling approach proposed by Zhang et al. (2009) which allows more robust conditional algorithms and greater integration of deepwater geological information. Bertoncello et al. (2013) have presented a workflow allowing better conditioning surface-based models to hard data from wells and seismic data, based on an optimization of the parameters controlling the model global and local spatial characteristics (Fig. 8). Their modeling started from a given base topography and stacked events (or thicknesses) to create a new surface from that base and repeated this process by taking the new surface as the base surface on which the next event is stacked. Notably, their work used two types of events: depositional events with positive thickness and erosional events with negative thickness. The erosion events are stochastically modeled constrained only by a simple rule that locations with a high gradient will have a higher probability of erosion than the regions with a low gradient. This is not necessarily the case since the intensity of erosions also depends on other properties such as grain concentration and flow thickness.

Applying the surface-based modeling method to turbidite lobes is an active research trend. The surface-based modeling methods have several advantages. First, the surfaces can be easily derived from seismic surveys and well-log correlations and hence can flexibly reproduce the geological interpretations, especially the large-scale interpretations (e.g., the sequence stratigraphy framework). Second, it has been proven effective in terms of integrating petrophysical properties to the geometrical model generated by the surface-based method. In addition, the published work introduced above has shown that surface-based models can well capture the geometries and compensational stacking pattern of turbidite lobes (Figs. 8, 9). Besides, they have successfully reproduced another level of hierarchy within lobe (i.e., small-scale flow event deposits). This flow event deposit scale is perhaps equivalent to the lobe element scale introduced by Prelat et al. (2009). Recent surface-based techniques presented by Sech et al. (2009) can represent discrete amalgamations with shallow-marine depositional systems and allows direct flow simulation without upscaling, perhaps reflecting a great improvement of the surface-based modeling. However, several shortcomings associated with these published surface-based methods exist. First, to date, only two-fold hierarchies have been considered for turbidite lobes despite these methods allow multi-hierarchical modeling. Second, detailed characterizations of turbidite outcrops reveal that the depositional surfaces within turbibite lobes can be rather complex, yet the surfaces generated by the
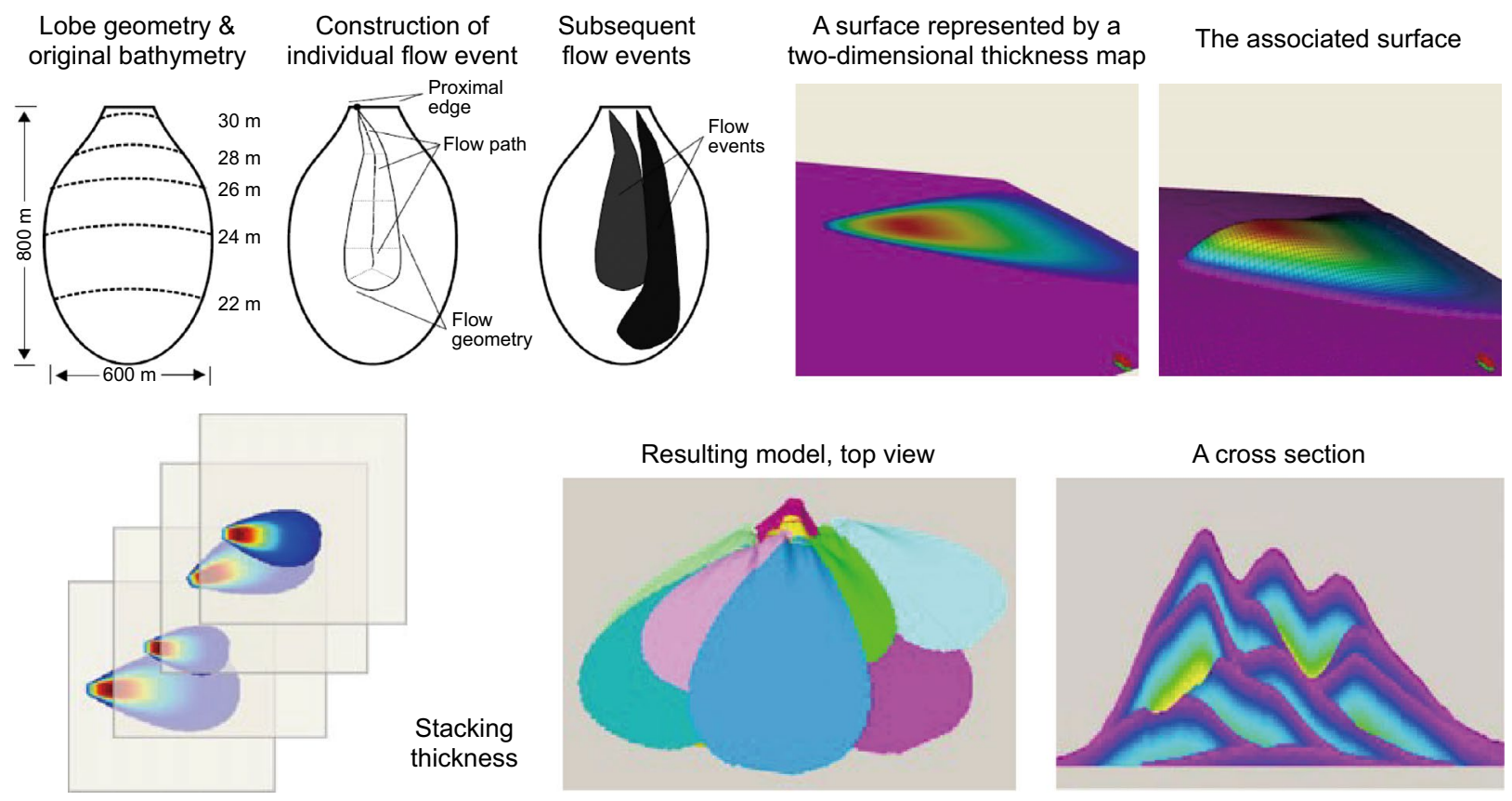

Fig. 8 The workflow of and resulting models of the surface-based modeling. Modified from Pyrcz et al. (2005) and Bertoncello et al. (2013) 

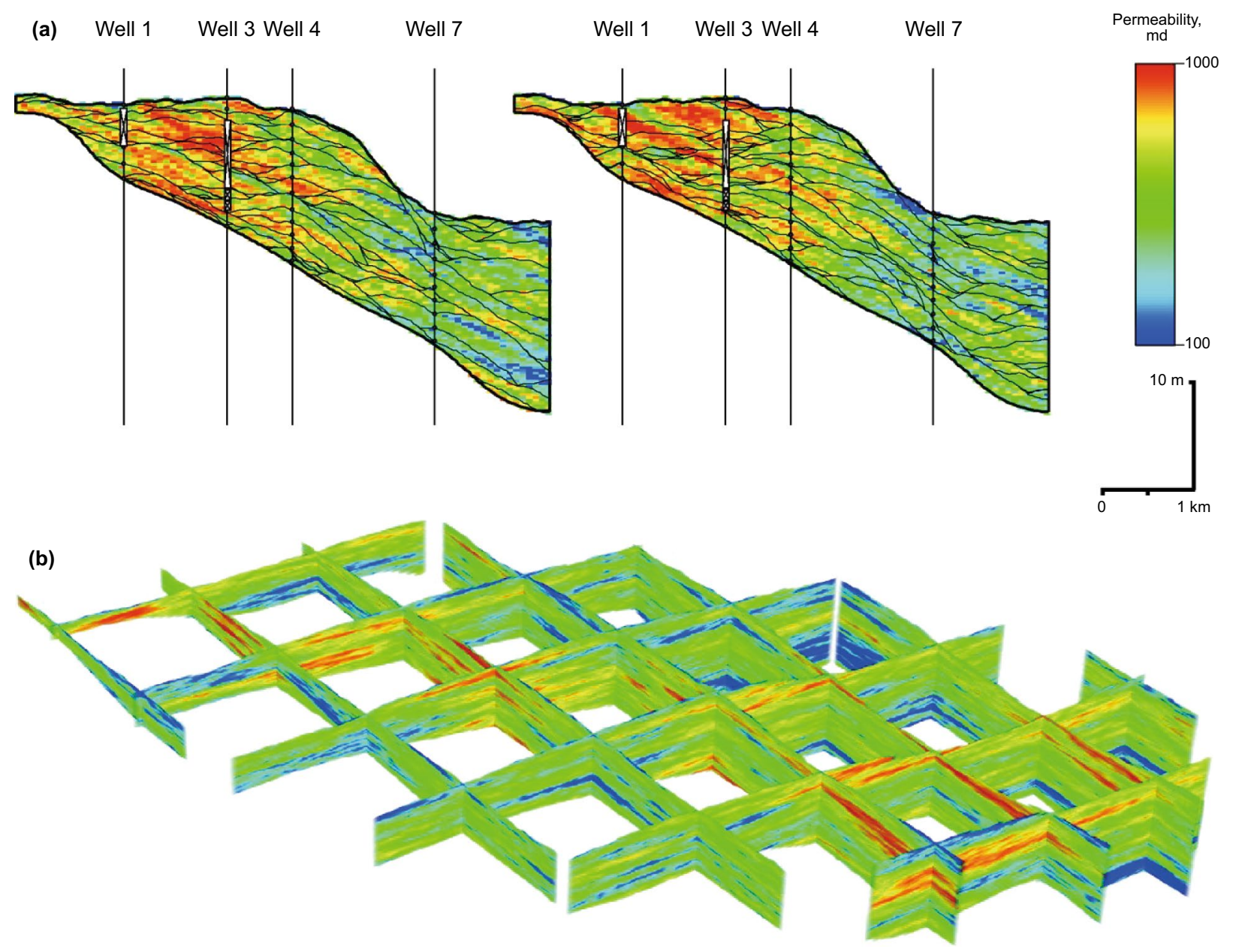

Fig. 9 Example output lobe model using process-based and surface-based modeling approach. a Two realizations of lobe model conditioned to well data and associated permeability trends. b A fence diagram of the first realization (30 times vertical exaggeration). Color scheme is the same as (b). Taken from Pyrcz et al. (2005)

surface-based modeling techniques are perhaps too simplistic. Third, the surface generation rules are not well quantified; amalgamations at different hierarchical scales have not been parameterized and therefore cannot fully represent the complex surface interactions (e.g., lobe surfaces are better preserved by lobe element surfaces).

\subsection{Two-point and multiple-point modeling}

Pixel-based modeling focuses on minimizing the estimation error between "two points", which is suitable for modeling heterogeneous, poorly connected sedimentary facies while incapable of capturing sedimentary facies with clear shapes and geometries (Deutsch and Tran 1999). Since deepwater reservoir (channels, lobes) are characterized by complex stacking of geological bodies with clear margins and geometries, few studies have applied "two-point" techniques to deepwater turbidite reservoirs. One exception includes Felletti (2004) where the Castagnola Fm turbidites outcrops are used as analogs to constrain a pixel-based modeling using a software HERESIM 4.0. Their models can honor the lithofacies proportions calculated from each outcrop logs, while is difficult to capture the reservoir architectures between outcrop logs. Falivene et al. (2006) built a suite of turbidite models using different modeling techniques based on turbidite outcrop data. Comparison of the models has demonstrated that two-point techniques cannot represent laterally continuous shale drapes and tend to overestimate the connectivity.

The workflow of MPS modeling allows integrating diverse type of data from wells, seismic and geological concepts, and can provide very realistic-looking architectures. Different simulation constraints can be imposed on the MPS model to account for spatial variations (both horizontal and vertical) of facies proportions and body geometry such as orientation and sizes (Strebelle and Levy 2008, Zhang 2008). Widely used MPS algorithms include SNESIM (Strebelle et al. 2003), FILTERSIM (Zhang et al. 
2006) and SIMPAT (Arpat and Caers 2004). The key to MPS is the design of training image. To this end, Pyrcz et al. (2008) proposed training image libraries for different depositional systems. Maharaja (2008) and Boucher (2010) developed unconditioned object-based techniques allows direct generation of training images. A unique advantage of MPS is that experiences of geologists can be effectively incorporated into models. For example, Zhang et al. (2016) established training images of deepwater turbidite channels based on depositional models interpreted from shallow, high frequency seismic data. Roy and Strebelle (2008) used multiple small-scale training images to mimic the large-scale complex interactions of shallow channels and deepwater turbidite lobes, resulting models can represent the complex architectures and honor various types of inputs such as facies proportions calculated from individual wells. Yunus (2016) used outcrop data and well data to build deepwater turbidite fan models using MPS techniques. Resulting models realistically reproduced the compensational stacking of 7 fans and complex distribution of channel, lobe, hemipelagic facies within each fan (Fig. 10). These works demonstrate the applicability of MPS to turbidite lobe reservoirs, yet they are not necessarily the modeling technique of choice for turbidite lobes because: (1) To date, it is difficult to model continuous properties (Pyrcz and Deustch 2014) and may not honor depositional regions (Strebelle and Levy 2008); (2) to reproduce detailed distribution and contact relationships of small-scale component units is still challenging; (3) the outcome of MPS modeling heavily relies on the training image which is a product of 3D architecture itself (Ringrose and Bentley 2015), in other words, MPS techniques require more pre-work than two-point techniques.

\subsection{Other modeling techniques}

Since the pioneering work of Hektoen and Holden (1999), aiming to better honor the geological concepts, considerable efforts have been focused on the process-mimicking modeling methods (Pyrcz and Deustch 2014). Conventional surface-based or object-based modeling is constructed to reproduce the final end-result of the reservoir architecture and properties, while process-mimicking modeling tends to integrate rules or geological processes at the very beginning. Therefore, process-mimicking methods are particularly suitable for those reservoirs whose inter-element stacking patterns and associated heterogeneities can be constrained to certain rules, for example the deepwater lobe reservoirs. Depending on the detailed aims, process-mimicking methods have a variety of terminologies, such as event-based (Pyrcz et al. 2005), rule-based (Pyrcz et al. 2015), surfacebased, process-oriented (Wen 2005), hybrid (Michael et al. 2010) and the like. Studies regarding application of processmimicking methods are vast and descriptions of such studies are summarized by Pyrcz et al. (2015) and not discussed herein. It should be noted that process-mimicking methods can be divided into the object-based front and the surfacebased front. In fact, surface-based modeling is a variant of object-based modeling and the line between these two methods is not that clear. In other words, the process-mimicking

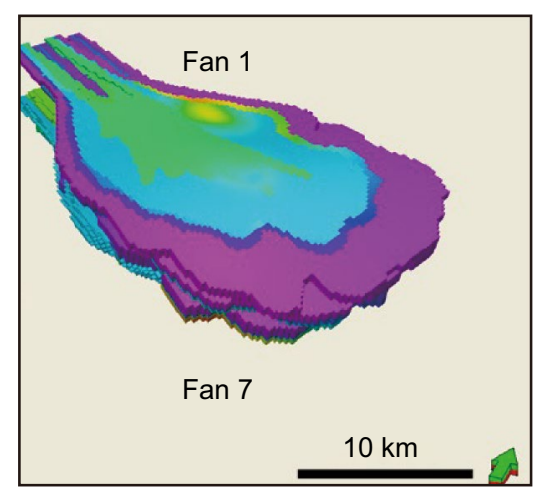

A

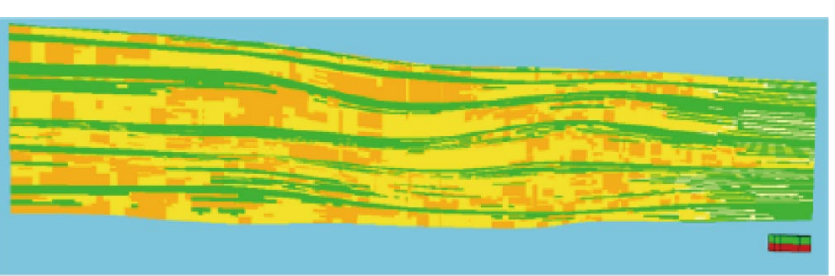

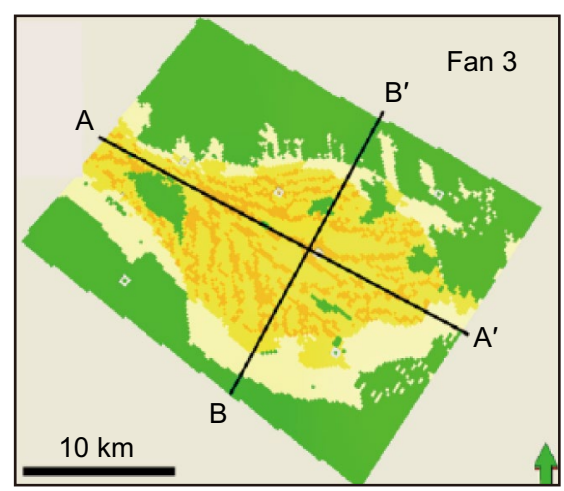

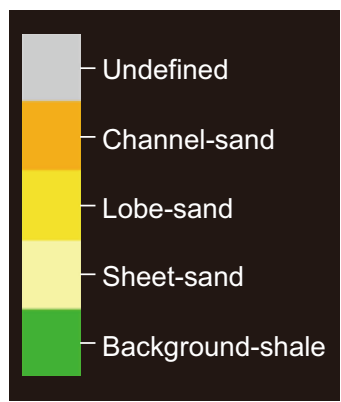

$A^{\prime} \quad B$

$B^{\prime}$

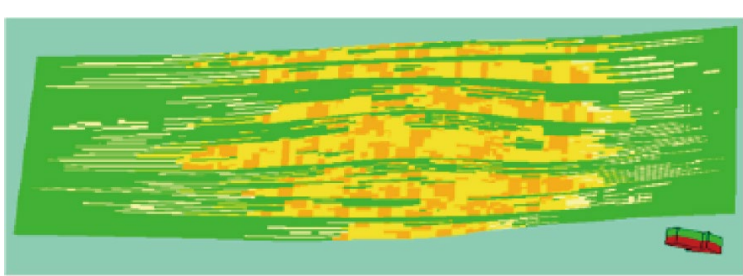

Fig. 10 Models built using Multiple-Point-Statistics methods including 7 deepwater fans, modified from Yunus (2016) 
method aims to provide a set of rules to mimic geological processes in such a way that reservoir elements are interacted in a geologically realistic manner; therefore, it is a combination of object-based, surface-based methods. Three types of rules are identified in process-mimicking methods: drafted rules, Markov rules and morpho-dynamical rules. In short, process-mimicking methods use geological rules in a forward manner to make the final model more realistic; theoretically, it is very suitable for modeling deepwater lobe reservoirs because it could well capture the lobe architectural hierarchy and the specific organization of architectural elements (e.g., compensational stacking or amalgamation of lobe elements). However, at present, such work on deepwater lobe reservoirs are relatively scarce and conditioning process-mimicking models to dense data remains a challenge.

The cellular automata method is another actively used method in terms of modeling deepwater turbidity systems. For instance, the CATS (Cellular Automata for Turbidite Systems) developed at IFPEN, France, which is indeed a forward process-based modeling method, has been utilized to model the deepwater turbidity flow processes while considering the impact of paleo-topography and structural background. For example, the CATS has been used to predict the sedimentary architecture of a turbidite reservoir in the Campos Basin, Brazil (Albertão et al. 2015), and demonstrated that the substratum composition and the depositional law are the most sensible parameters by performing a sensitivity analysis. However, this set of modeling work focuses on modeling the large-scale features such as increasing flow velocities in confined settings and successive filling of contiguous sub-basins, although they improved the data conditioning and running speed, they might not be suitable when applied to practical reservoir modeling. The reasons are as follows; first, it is extremely difficult to reproduce the reservoir-scale architecture and the associated heterogeneity; second, the modeling results are highly dependent on the input parameters of flow properties and are perhaps not the answer to improve the geological realism, at least presently.

\section{Discussions}

In real reservoir modeling work, three factors are particularly considered for modeling techniques selection: (1) geological complexity; (2) types and properties of available data; (3) pros and cons of modeling techniques. As stated above, the geological complexity of turbidite lobes is mainly characterized by the geometries and stacking patterns of sand-prone lobe component units and the spatial distribution of their shale barriers at different hierarchical levels. Lobe complexes are separated by basinal thick pelagic/hemipelagic mudstones reflecting allogenic controls (e.g., relative sea level). It therefore seems practical to deterministically define such large-scale hierarchical components at the first step. Smaller scale hierarchical components are controlled by autogenic factors (e.g., channel avulsion). Within a lobe, lobe elements display complex stacking pattern with occasional amalgamations. Within a lobe element, rapid depositions result in poorly preserved, discontinuous mudstones. The lateral and vertical heterogeneity at sandstone bed scale is rather low due to high sandstone amalgamations. In terms of reproducing the geological complexity of turbidite lobes, object-based techniques offer the most appropriate way to model multiple hierarchies and geometric and stacking characteristics of hierarchical components and associated shales. Surface-based/process-mimicking techniques also prove effective for reproducing hierarchies and realistic architectures, but have not parameterized the amalgamations between hierarchical components, representation of geological bodies which are very laterally extensive can be also difficult. Pixel-based techniques are perhaps not suitable since turbidite lobes are characterized by clear shapes and geometries (Fig. 11).

In turbidite lobe reservoir exploration and development, seismic data are characterized by high lateral resolution, but vertical resolution is often too low to represent the vertical heterogeneity; the number of wells is often limited due to the high cost of drilling, continuous coring are highly expensive. A recent trend is to use databases based on quantitative outcrop characterizations (Funk and Pyles 2012; Howell et al. 2014; Zhang et al. 2017) to guide subsurface reservoir modeling. MPS techniques allow conditioning to several types of data and could directly use outcrops as training images. Pixel-based techniques allow limitless conditioning to well data; however, the variograms calculated from well data are perhaps incapable of reflecting the reservoir architectures at inter-well regions (Fig. 11). Object-based techniques require strong geological knowledge and quantitative parameterization of object dimensions, shapes and amalgamations. On the premise, object-based techniques are appropriate to model the heterogeneity within lobe reservoirs. Condition object-based models to dense well data can be very difficult and time-consuming. Geological concepts and quantified parameters gained from outcrops could offset this disadvantage. Meanwhile, it is a common case that only a few wells are drilled for turbidite reservoirs which are often at scales of several kms to 10s' kms. Therefore, this difficulty of conditioning to dense well data might not become an issue for object-based modeling in this circumstance. Process-based techniques have the worst capability to honor seismic and well data. In terms of conditioning to dense data, surfacebased techniques perhaps lie intermediate of process-based and object-based techniques (Fig. 11).

Heterogeneities at different scales (pore-laminae-architectural element-static reservoir model-dynamic flow model) could all impact the final flow performances (Ringrose and 


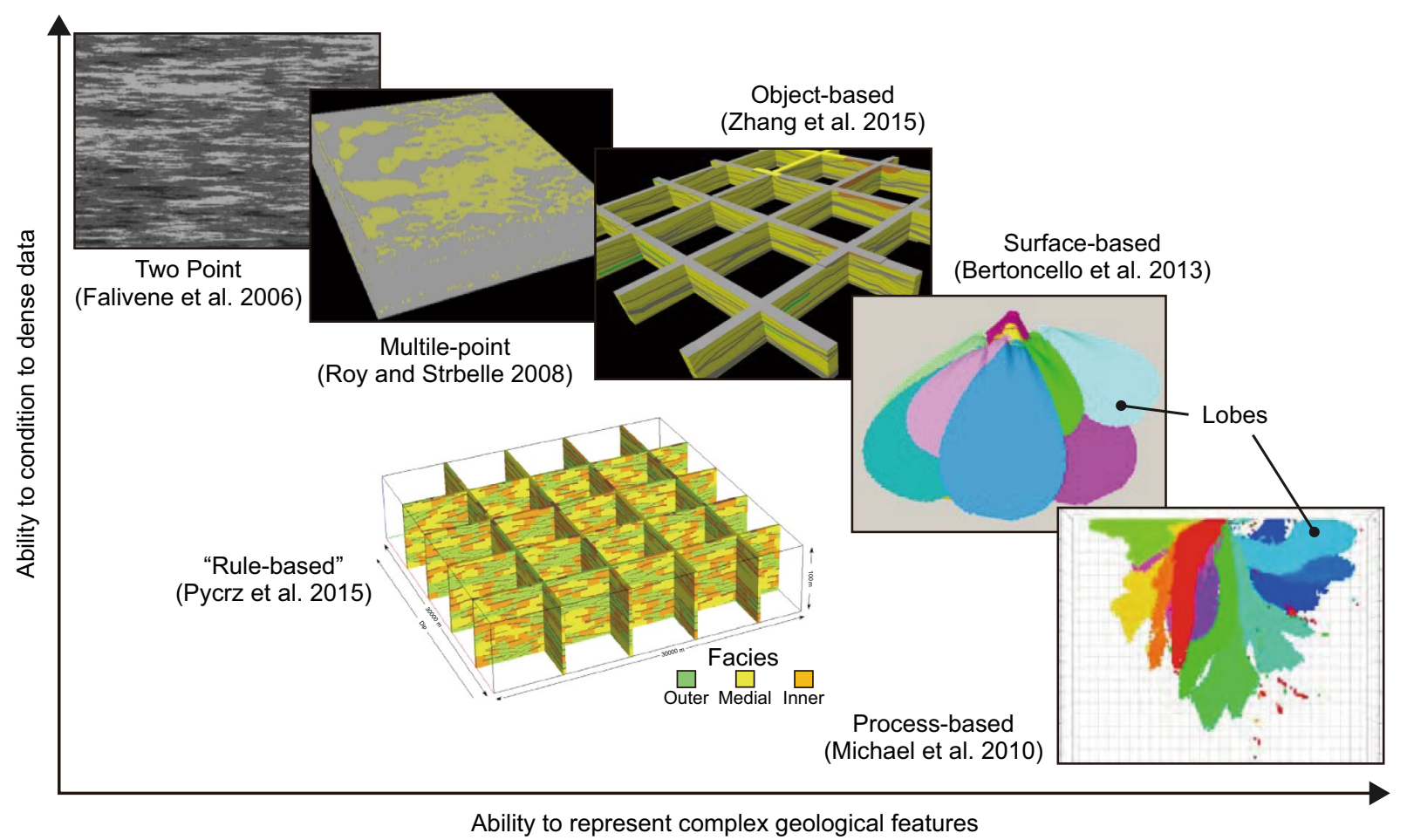

Fig. 11 Comparison of different stochastic modeling techniques

Bentley 2015). Heterogeneities at which hierarchical scale is the focus for reservoir modeling could vary depend on the nature of the depositional system and specific targets at different exploration and development stages (Wu 2010). Commonly, pore-laminae characteristics are not considered in reservoir modeling because of data inaccessibility and heavy computing power required. For turbidite lobe reservoirs in specific, large-scale lobe complexes and lobes have great lateral connectivity ( $\mathrm{km}$-tens of $\mathrm{kms}$ ) but low to zero vertical connectivity. The sandstone-scale bed connectivity has been demonstrated to be the key control on static connectivity and flow performances (King 1990; Stephen et al. 2001; Falivene et al. 2006; Manzocchi et al. 2007). Further, modeling honoring the complete bed-lobe element-lobe-lobe complex hierarchical scales has demonstrated that the connectivity and flow performances are both poor when lobe elements are poorly connected (which is normal in natural turbidite systems) even if sandstone beds are $100 \%$ connected (Zhang et al. 2015). Therefore, hierarchical characterization and stochastic modeling of deepwater turbidite lobe reservoirs should focus on lobe element and sandstone bed scale, given that lobes and lobe complexes or other hierarchically higher components are barely inter-connected.

Deepwater channels which feed downstream turbidite lobes are also promising hydrocarbon reservoirs. Architectural hierarchy, stacking patterns and facies associations of deepwater channels are widely studied and modeled (e.g., Falivene et al. 2006; Labourdette 2007; Zhang et al. 2016). In general, the modeling techniques discussed in the present paper can be equally applied to model deepwater channels. However, to date, few modeling studies have focused on the transition belt from upstream feeder channels to downstream lobes. The transition between channels and lobes ("Channel-lobe transition zone", Wynn et al. 2002) are critical in terms of linking different depositional environment (slope vs basin-floor) and flow rheology (erosional-prone vs depositional-prone). More efforts should be paid to how turbidite lobes are evolved and linked with feeder channels if a complete source-to-sink geological model is to build. Additionally, hyperpycnites could be commonly developed in deep sea (Migeon et al. 2012) and deep lacustrine environment (Yang et al. 2017). Characterized by couplets of basal upward-coarsening interval and upper upward-fining interval, hyperpycnite deposits are often developed associated with turbidites and debrites. As potential hydrocarbon reservoirs, hyperpycnites in deepwater environment are perhaps overlooked. Modeling methods discussed herein could be applied to hyperpycnal lobes which have similar geometrical characteristics and stacking patterns with turbidite lobes, despite their internal facies associations may vary. 


\section{Conclusions}

1. Deepwater lobe reservoir architecture can be described within an architectural hierarchy which represents sedimentary cycles controlled by allogenic or autogenic factors. Deepwater lobe reservoirs are generally structured into a multiple-fold hierarchy from small-scale beds to large-scale lobe complexes, at each hierarchical scale, thick sand-prone units are always draped by thin, finegrained units. Unless amalgamated or faulted, a specific hierarchical element is draped by shales and thus not connected with its contiguous hierarchical element, suggesting the amalgamation is the key for reservoir connectivity.

2. Existing modeling work on turbidite lobes include pixelbased and multiple-point statistics, object-based methods, surface-based methods, process-oriented methods, process-based methods and process-mimicking methods. Each modeling method has unique features such as input statistics, ability to honor the inputs. For example, conventional pixel-based techniques allow limitless conditioning to well data yet could not reproduce reservoir architectures with clear shapes and geometries; processbased modeling and object-based modeling methods have great advantage in terms of honoring geological realism but dense data conditioning for these two methods are very difficult, while surface-based and processoriented modeling methods are likely the opposite. For turbidite lobes, object-based modeling methods could well represent the internal architectural hierarchy and amalgamations, hence could reproduce the complex interactions of shale drapes and sandy units that have great reservoir potential to the best degree. However, how to condition object-based models to dense data sets remains a challenge. In short, to choose the modeling methods depends on the specific content and goals of the project, for instance, the available data, the model scale and the depositional environment.

3. Notwithstanding specific pros and cons, modeling methods of deepwater turbidite lobes reviewed herein allow $3 \mathrm{D}$ visualization and reproduction of reservoir architecture and heterogeneity, sensitivity analysis can be easily performed, uncertainty can be quantitatively assessed, which facilitate the decision-making for all stages of field life. This review provides a small window for better understanding the deepwater lobe architecture and connectivity, and for a purpose-oriented selection of existing modeling methods according to specific aims of a project. In contrast to conventional modeling with a single, all-purpose method, a hybrid of different modeling methods is more flexible and becoming more popular.
4. Recent modeling work mainly focus on reproduce the sedimentological characteristics of deepwater lobe reservoirs, while other factors, such as topography (e.g., salt domes) and structural factors, could also play an important role in controlling the final reservoir architectures (Pan et al. 2012). Modeling methods incorporating such factors are still scarce; besides, more attention should be paid to model the reservoir dynamic behaviors.

Acknowledgements This paper is based on first author's PhD work at University College Dublin, Prof. Tom Manzocchi and Prof. Peter Haughton are thanked for their great supervisions. China Scholarship Council, University College Dublin are thanked for the financial support. Five anonymous reviewers are thanked for insightful and constructive reviews of this manuscript.

Open Access This article is licensed under a Creative Commons Attribution 4.0 International License, which permits use, sharing, adaptation, distribution and reproduction in any medium or format, as long as you give appropriate credit to the original author(s) and the source, provide a link to the Creative Commons licence, and indicate if changes were made. The images or other third party material in this article are included in the article's Creative Commons licence, unless indicated otherwise in a credit line to the material. If material is not included in the article's Creative Commons licence and your intended use is not permitted by statutory regulation or exceeds the permitted use, you will need to obtain permission directly from the copyright holder. To view a copy of this licence, visit http://creativecommons.org/licenses/by/4.0/.

\section{References}

Aas TE, Basani R, Howell J, et al. Forward modelling as a method for predicting the distribution of deep-marine sands: an example from the Peïra Cava Sub-basin. Geol Soc Lond Spec Publ. 2014;387(1):247-69. https://doi.org/10.1144/sp387.9.

Ainsworth RB. Sequence stratigraphic-based analysis of reservoir connectivity: influence of depositional architecture-a case study from a marginal marine depositional setting. Pet Geosci. 2005;11(3):257-76. https://doi.org/10.1144/1354-079304-638.

Albertão GA, Eschard R, Mulder T, et al. Modeling the deposition of turbidite systems with Cellular Automata numerical simulations: a case study in the Brazilian offshore. Mar Pet Geol. 2015;59(59):166-86. https://doi.org/10.1016/j.marpe tgeo.2014.07.010.

Arpat GB, Caers J. A multiple-scale, pattern-based approach to sequential simulation. In: GEOSTAT 7th inernational geostatistics congress, Banff, Canada. 2004. https://doi. org/10.1007/978-1-4020-3610-1_26.

Athmer W, Groenenberg RM, Luthi SM, et al. Relay ramps as pathways for turbidity currents: a study combining analogue sandbox experiments and numerical flow simulations. Sedimentology. 2010;57(3):806-23. https://doi.org/10.111 1/j.1365-3091.2009.01120.x.

Bertoncello A, Sun T, Li H, et al. Conditioning surface-based geological models to well and thickness data. Math Geosci. 2013;45(7):873-93. https://doi.org/10.1007/s11004-013-9455-4.

Boucher A. Considering complex training images with search tree partitioning. Comput Geosci. 2010;35(6):1151-8. https://doi. org/10.1016/j.cageo.2008.03.011. 
Caers J. Geostatistical reservoir modelling using statistical pattern recognition. J Pet Sci Eng. 2001;29(3-4):177-88. https://doi. org/10.1016/s0920-4105(01)00088-2.

Chapin M, Davies P, Gibson J, et al. Reservoir architecture of turbidite sheet sandstones in laterally extensive outcrops, Ross Formation, western Ireland. Submar Fans Turbid Syst. 1994. https://doi. org/10.5724/gcs.94.15.0053.

Deptuck ME, Piper DJ, Savoye B, et al. Dimensions and architecture of late Pleistocene submarine lobes off the northern margin of East Corsica. Sedimentology. 2008;55(4):869-98. https://doi.org/10.1 111/j.1365-3091.2007.00926.x.

Deutsch C, Tran T. Simulation of deepwater lobe geometries with object-based modelling: Lobesim. 1999. Centre for Computational Geostatistics 1st Annual Report. University of Alberta. http://www.uofaweb.ualberta.ca/ccg//pdfs/1999\%2004LobeMo deling1.pdf.

Deutsch C, Tran T. FLUVSIM: a program for object-based stochastic modeling of fluvial depositional systems. Comput Geosci. 2002;28(4):525-35. https://doi.org/10.1016/j.cageo.2008.09.012.

Elfenbein C, Husby $\varnothing$, Ringrose P. Geologically based estimation of kv/kh ratios: an example from the Garn Formation, Tyrihans field, mid-Norway, Geological Society, London, Petroleum Geology Conference series. of Geological Society London. 2005; pp. 537-543. https://doi.org/10.1144/0060537.

Falivene O, Arbués P, Gardiner A, et al. Best practice stochastic facies modeling from a channel-fill turbidite sandstone analog (the Quarry outcrop, Eocene Ainsa basin, northeast Spain). AAPG Bull. 2006;90(7):1003-29. https://doi.org/10.1306/02070605112.

Felletti F. Statistical modelling and validation of correlation in turbidites: an example from the Tertiary Piedmont Basin (Castagnola Fm., Northern Italy). Mar Pet Geol. 2004;21(1):23-39. https://doi. org/10.1016/j.marpetgeo.2003.11.006.

Funk JE, Pyles DR. Quantification of static connectivity between deepwater channels and stratigraphically adjacent architectural elements using outcrop analogs. AAPG Bull. 2012;96(2):277-300. https://doi.org/10.1306/07121110186.

Gervais A, Mulder T, Savoye B, et al. Sediment distribution and evolution of sedimentary processes in a small sandy turbidite system (Golo system, Mediterranean Sea): implications for various geometries based on core framework. Geo-Mar Lett. 2006;26(6):37395. https://doi.org/10.1007/s00367-006-0045-z.

Groenenberg RM, Hodgson DM, Prélat A, et al. Flow-deposit interaction in submarine lobes: insights from outcrop observations and realizations of a process-based numerical model. J Sediment Res. 2010;80(3):252-67. https://doi.org/10.2110/jsr.2010.028.

Grundvåg SA, Johannessen EP, Hell-Hansen W, et al. Depositional architecture and evolution of progradationally stacked lobe complexes in the Eocene Central Basin of Spitsbergen. Sedimentology. 2014;61(2):535-69. https://doi.org/10.1111/sed.12067.

Hawie N, Covault JA, Dunlap D, et al. Slope-fan depositional architecture from high-resolution forward stratigraphic models. Mar Pet Geol. 2018;91:576-85. https://doi.org/10.1016/j.marpe tgeo.2017.12.033

Hektoen AL, Holden L. Bayesian modelling of sequence stratigraphic bounding surfaces. Geostat Wollongong. 1999;96:339-49.

Holden L, Hauge R, Skare O, Skorstad A. Modeling of fluvial reservoirs with object models. Math Geol. 1998;30(5):473-96. https ://doi.org/10.1023/A:1021769526425.

Huang J, Mu L, Chen H, et al. Preliminary study on a depositional interface-based reservoir modeling method. Pet Explor Dev. 2013;40(5):591-4. https://doi.org/10.1016/s1876-3804(13)60083 $-\mathrm{x}$.

Howell JA, Martinius AW, Good TR. The application of outcrop analogues in geological modelling: a review, present status and future outlook. Geol Soc Lond Spec Publ. 2014;387(1):1-25. https://doi. org/10.1144/sp387.12.
King P. The connectivity and conductivity of overlapping sand bodies. North Sea Oil Gas Reserv-II. 1990. https://doi. org/10.1007/978-94-009-0791-1_30.

Labourdette R. Integrated three-dimensional modeling approach of stacked turbidite channels. Aapg Bull. 2007;91(11):1603-18. https://doi.org/10.1306/06210706143.

Larue DK, Hovadik J. Connectivity of channelized reservoirs: a modelling approach. Pet Geosci. 2006;12(4):291-308. https://doi. org/10.1144/1354-079306-699.

Larue DK, Legarre H. Flow units, connectivity, and reservoir characterization in a wave-dominated deltaic reservoir: meren reservoir, Nigeria. Aapg Bull. 2004;88(3):303-24. https://doi. org/10.1306/10100303043.

Li S, Liu X, Wang J, et al. Improvement of the Alluvsim algorithm modeling based on depositional processes. Acta Pet Sin. 2013;34(1):140-4. https://doi.org/10.7623/syxb201301017 (In Chinese)

Maharaja A. TiGenerator: object-based training image generator. Comput Geosci. 2008;34(12):1753-61. https://doi. org/10.1016/j.cageo.2007.08.012.

Manzocchi T, Walsh JJ, Tomasso M, et al. Static and dynamic connectivity in bed-scale models of faulted and unfaulted turbidites. Geol Soc Lond Spec Publ. 2007;292(1):309-36. https:// doi.org/10.1144/sp292.18.

Marini M, Milli S, Moscatelli M. Facies and architecture of the Lower Messinian turbidite lobe complexes from the Laga Basin (central Apennines, Italy). J Mediterr Earth Sci. 2011;3:45-72. https://doi.org/10.3304/JMES.2011.005.

Marini M, Milli S, Ravnas R, et al. A comparative study of confined vs semi-confined turbidite lobes from the Lower Messinian Laga Basin (Central Apennines, Italy): implications for assessment of reservoir architecture. Mar Pet Geol. 2015;6(3):142-65. https://doi.org/10.1016/j.marpetgeo.2015.02.015.

Marini M, Felletti F, Milli S, et al. The thick-bedded tail of turbidite thickness distribution as a proxy for flow confinement: examples from tertiary basins of central and northern Apennines (Italy). Sed Geol. 2016;34(1):96-118. https://doi.org/10.1016/j.sedge o.2016.05.006.

Michael HA, Li H, Boucher A, et al. Combining geologic-process models and geostatistics for conditional simulation of 3-D subsurface heterogeneity. Water Resour Res. 2010;46(5):1532-5. https://doi.org/10.1029/2009wr008414.

Migeon S, Mulder T, Savoye B, et al. Hydrodynamic processes, velocity structure and stratification in natural turbidity currents: results inferred from field data in the Var Turbidite System. Sediment Geol. 2012;245-246(1):48-62. https://doi.org/10.1016/j. sedgeo.2011.12.007.

Mutti E, Normark WR. Comparing examples of modern and ancient turbidite systems: problems and concepts. Mar Clastic Sediment. 1987. https://doi.org/10.1007/978-94-009-3241-8_1.

Pan M, Zhaoliang LI, Gao Z, et al. 3-D geological modeling-concept, methods and key techniques. Acta Geol Sin. 2012;86(4):10316. https://doi.org/10.1111/j.1755-6724.2012.00727.x (In Chinese).

Prelat A, Hodgson D, Flint S. Evolution, architecture and hierarchy of distributary deep-water deposits: a high-resolution outcrop investigation from the Permian Karoo Basin, South Africa. Sedimentology. 2009;56(7):2132-54. https://doi.org/10.111 1/j.1365-3091.2009.01073.x.

Pyrcz M, Deutsch C. Geostatistical reservoir modeling. Oxford: Oxford University Press; 2014. p. 113.

Pyrcz M, Deutsch C. Stochastic surface modeling in mud rich, finegrained turbidite lobes. AAPG Annual Meeting, Salt Lake City, Utah. 2003.

Pyrcz MJ, Boisvert JB, Deutsch CV. A library of training images for fluvial and deepwater reservoirs and associated code. Comput 
Geosci. 2008;34(5):542-60. https://doi.org/10.1016/j.cageo .2007.05.015.

Pyrcz M, Boisvert J, Deutsch C. ALLUVSIM: a program for eventbased stochastic modeling of fluvial depositional systems. Comput Geosci. 2009;35(8):1671-85. https://doi.org/10.1016/j.cageo .2008.09.012.

Pyrcz MJ, Catuneanu O, Deutsch CV. Stochastic surface-based modeling of turbidite lobes. Aapg Bull. 2005;89(2):177-91. https:// doi.org/10.1306/09220403112.

Pyrcz MJ, Sech RP, Covault JA, et al. Stratigraphic rule-based reservoir modeling. Bull Can Pet Geol. 2015. https://doi.org/10.2113/gscpg bull.63.4.287.

Reza ZA, Pranter MJ, Weimer P. ModDRE: a program to model deepwater-reservoir elements using geomorphic and stratigraphic constraints. Comput Geosci. 2006;32(8):1205-20. https://doi. org/10.1016/j.cageo.2005.11.004.

Ringrose P, Bentley M. Reservoir model design: a practitioner's guide. Dordrecht, The Netherlands: Springer; 2015. https://doi. org/10.1007/978-94-007-54.

Romans BW, Hubbard SM, Graham SA. Stratigraphic evolution of an outcropping continental slope system, Tres Pasos Formation at Cerro Divisadero, Chile. Sedimentology. 2009;56(3):737-64. https://doi.org/10.1111/j.1365-3091.2008.00995.x.

Roy P, Strebelle S. Capturing depositional processes using MPS simulation with multiple training images. AAPG Annual Convention \& Exhibition, San Antonio. 2008.

Saller A, Werner K, Sugiaman F, et al. Characteristics of Pleistocene deep-water fan lobes and their application to an upper Miocene reservoir model, offshore East Kalimantan, Indonesia. AAPG Bull. 2008;92(7):919-49. https://doi.org/10.1306/03310807110.

Scaglioni P, Ruvo L, Cozzi M. Implicit net-to-gross in the petrophysical characterization of thin-layered reservoirs. Pet Geosci. 2006;12(4):325-33. https://doi.org/10.1144/1354-079305-694.

Sech R, Jackson M, Hampson G. Three-dimensional modeling of a shoreface-shelf parasequence reservoir analog: part 1. Surfacebased modeling to capture high-resolution facies architecture. Aapg Bul. 2009;93(9):1155-81. https://doi.org/10.1306/05110 908144.

Seifert D, Jensen JL. Using sequential indicator simulation as a tool in reservoir description: issues and uncertainties. Math Geol. 1999;31(5):527-50. https://doi.org/10.1023/A:1007563907124.

Seifert D, Jensen JL. Object and pixel-based reservoir modeling of a braided fluvial reservoir. Math Geol. 2000;32(5):581-603. https ://doi.org/10.1023/A:1007562221431.

Stephen KD, Clark JD, Gardiner AR. Outcrop-based stochastic modeling of turbidite amalgamation and its effects on hydrocarbon recovery. Pet Geosci. 2001;7(2):163-72. https://doi.org/10.1144/ petgeo.7.2.163.

Strebelle S, Levy M. Using multiple-point statistics to build geologically realistic reservoir models: the MPS/FDM workflow. Geol Soc Lond Spec Publ. 2008;309(1):67-74. https://doi.org/10.1144/ sp309.5.

Strebelle S, Payrazyan K, Caers J. Modeling of a deepwater turbidite reservoir conditional to seismic data using principal component analysis and multiplepoint geostatistics. SPE J. 2003;8(3):227-35. https://doi.org/10.2118/85962-pa.

Tetzlaff DM. The combined use of sedimentary process modeling and statistical simulation in reservoir characterization. Softw Pract Exp. 1991. https://doi.org/10.2118/22759-ms.
Wang Y, Yin T, Deng Z, et al. Terminal distributary channels in fluvialdominated delta systems from numerical simulation of hydrodynamics. Geol Sci Technol Inf. 2016;35(1):44-52. https://doi. org/10.2110/jsr.2006.026.

Wang YC, Pyrcz MJ, Catuneanu O, et al. Conditioning 3D object-based models to dense well data. Comput Geosci. 2018;115:1-11. https ://doi.org/10.1016/j.cageo.2018.02.006.

Wen R. SBED Studio - an integrated workflow solution for multi-scale geo-modelling. In: European Association of Geoscientists and Engineers, 67th conference, Madrid. 2005.

Wu SH, Yue DL, Liu JM, et al. Hierarchy modeling of subsurface palaeochannel reservoir architecture. Sci China. 2008a;51(S2):126-37. https://doi.org/10.1007/s11430-008-0624-0.

Wu S. Reservoir characterization and modeling. Beijing: Petroleum Press; 2010 (In Chinese).

Wu S, Yue D, Liu J, et al. Hierarchical modeling of subsurface paleochannel reservoir architecture. Sci China. 2008b;38(S1):111-21. https://doi.org/10.1007/s11430-008-0624-0.

Wynn RB, Piper DJ, Gee MJ. Generation and migration of coarsegrained sediment waves in turbidity current channels and channel-lobe transition zones. Mar Geol. 2002;192(1):59-78. https:// doi.org/10.1016/s0025-3227(02)00549-2.

Yang R, Jin Z, Van Loon AJ, et al. Climatic and tectonic controls of lacustrine hyperpycnite origination in the Late Triassic Ordos Basin, central China: implications for unconventional petroleum development. AAPG Bull. 2017;101(1):95-117. https://doi. org/10.1306/08151817360.

Yin $\mathrm{Y}$, Wu S, Zhang $\mathrm{C}$, et al. A skeleton-based multiple point geostatistics for reservoir stochastic modeling. Sci China. 2008;38(S2):157-64. https://doi.org/10.1007/s11430-009-5004-x.

Yunus F. Facies modelling based on multi-point statistics (MPS) in submarine fan deposits. 2016; Msc Thesis, University of Stavanger, Norway.

Zhang T. Incorporating geological conceptual models and interpretations into reservoir modeling using multiple-point geostatistics. Earth Sci Front. 2008;15(1):26-35. https://doi.org/10.1016/s1872 -5791(08)60016-0.

Zhang T, Switzer P, Journel A. Filter-based classification of training image patterns for spatial simulation. Math Geol. 2006;38(1):6380. https://doi.org/10.1007/s11004-005-9004-X.

Zhang X, Pyrcz MJ, Deutsch CV. Stochastic surface modeling of deepwater depositional systems for improved reservoir models. J Pet Sci Eng. 2009;68(s1-2):118-34. https://doi.org/10.1016/j.petro 1.2009.06.019.

Zhang L, Manzocchi T, Haughton P. Impact of sedimentological hierarchy on sandstone connectivity in deep-water lobes-an object-based modelling approach. In: 75th EAGE conference \& exhibition incorporating SPE EUROPEC 2013. https://doi. org/10.3997/2214-4609.20130778.

Zhang L, Manzocchi T, Pontén A. Hierarchical parameterisation and modelling of deep-water lobes. Pet Geostat. 2015. https://doi. org/10.3997/2214-4609.201413606.

Zhang W, Duan T, Liu Z, et al. Application of multi-point geostatistics in deep-water turbidity channel simulation: a case study of Plutonio oilfield in Angola. Pet Explor Dev. 2016;43(3):403-10. https ://doi.org/10.1016/s1876-3804(16)30051-9.

Zhang L, Mao P, Wang H, et al. Deepwater turbidite lobe deposits: a review of the research frontiers. Acta Geol Sin (Engl Ed). 2017;91(1):283-300. https://doi.org/10.1111/1755-6724.13078. 